\title{
Polissacarídeos de parede celular fúngica: purificação e caracterização
}

\section{Fungal cell wall polysaccharides: purification and characterization}

\author{
Eliane Kaori Fukuda'; ${ }^{1}$ Ana Flora Dalberto Vasconcelos²; \\ Andreza Cândido Matias'; ; Aneli de Melo Barbosa ${ }^{1}$; \\ Robert Frans Huibert Dekker ${ }^{3}$; Maria de Lourdes Corradi da Silva ${ }^{4 *}$
}

\section{Resumo}

A parede celular é uma estrutura rígida, essencial para a sobrevivência dos fungos, e o conhecimento de sua composição poderá ser útil para o desenvolvimento de novas drogas antifúngicas. Neste contexto, os polissacarídeos estão entre os seus principais componentes que têm sido alvos de intensa investigação científica. As informações, provenientes do conhecimento da estrutura dessas macromoléculas, poderão ser valiosas para o entendimento dos mecanismos de síntese da parede celular de fungos causadores de patologias, tanto em plantas quanto em animais. A determinação da estrutura química de um endopolissacarídeo deve ser precedida por experimentos de extração e purificação. As extrações, geralmente conduzidas em soluções aquosas neutras e/ou alcalinas, separaram as biomoléculas em grupos, de acordo com suas solubilidades. Os extratos, contendo mistura de polissacarídeos, podem ser purificados pela combinação de métodos químicos e cromatográficos. Após purificação, os polissacarídeos considerados homogêneos são caracterizados estruturalmente com as técnicas convencionais em química de carboidratos tais como hidrólise, metilação, FT-IR e RMN- ${ }^{13} \mathrm{C}$ e ${ }^{1} \mathrm{H}$. Esta revisão tem como proposta efetuar um levantamento das principais investigações científicas conduzidas com o objetivo de caracterizar polissacarídeos da parede celular fúngica.

Palavras-chave: Biomassa, parede celular fúngica, polissacarídeos, caracterização química

\begin{abstract}
The cell wall is a rigid structure essential for the survival of fungi. A knowledge of its composition is therefore useful for the development of novel anti-fungal drugs. In this context, polysaccharides as main components of the fungal cell wall have been the subject of intense scientific study over the years. The information gained from the knowledge of the structure of these macrobiomolecules could therefore be valuable in elucidating the mechanisms of their biosynthesis in the cell walls of pathogenic fungi infecting plants and animals alike. Determination of the chemical structures of these polysaccharides (endo) is preceded by their extraction and purification. The extractions, generally lead to neutral and/ or alkaline soluble biopolymers in groups according to their solubilities. Mixtures of polysaccharides in these extracts can then be purified by a combination of chemical and chromatographic methods.
\end{abstract}

\footnotetext{
1 Programa de pós-graduação em Biotecnologia, Departamento de Bioquímica e Biotecnologia, Centro de Ciências Exatas, Universidade Estadual de Londrina.

2 Departamento de Física, Química e Biologia, Faculdade de Ciências e Tecnologia, Universidade Estadual Paulista Júlio de Mesquita Filho.

3 Universidad de Castilla-La Mancha - IRICA, 13071 Ciudad Real, España.

4 Programa de pós-graduação em Biotecnologia, Departamento de Bioquímica e Biotecnologia, Centro de Ciências Exatas, Universidade Estadual de Londrina, Departamento de Física, Química e Biologia, Faculdade de Ciências e Tecnologia, Universidade Estadual Paulista Júlio de Mesquita Filho. Email: corradi@fct.unesp.br

* Autor para correspondência
} 
Following purification, the polysaccharides, considered homogeneous, can be characterized structurally using conventional techniques of carbohydrate chemistry, such as hydrolysis, methylation analysis, and FT-IR, ${ }^{13} \mathrm{C}$ - and ${ }^{1} \mathrm{H}$ - NMR spectroscopy. This review surveys the main scientific literature that characterizes polysaccharides constituting the fungal cell wall.

Key words: Biomass, fungal cell wall, polysaccharides, chemical characterization

\section{Introdução}

Os biopolímeros, como proteínas e polissacarídeos, representam os mais abundantes compostos orgânicos da biosfera, exibindo importantes propriedades e diferentes aplicações, relacionadas com suas características químicas.

Fungos, bactérias eplantasvêmsendopesquisados como potenciais fontes dessas macromoléculas, principalmente de polissacarídeos. A possibilidade de aplicação desses compostos na saúde humana, assim como em outras áreas, tem levado a intensivos estudos relacionados à sua extração e caracterização (GERN et al., 2007).

Polissacarídeos bioativos isolados da parede celular fúngica têm sido caracterizados como homopolímeros, heteropolímeros ou, ainda, encontram-se ligados aos resíduos de proteínas formando complexos polissacarídeo-proteína (KIM et al., 2003; ZHANG et al., 2002).

Embora estudos sobre a composição da parede celular de vários fungos sejam efetuados, o maior número de informações disponíveis na literatura está relacionado com a estrutura de parede do ascomiceto Saccharomyces cerevisiae, que é composta por $\beta$-Dglucanas, quitinas e manoproteínas (KAPTEYN; VAN DEN ENDE; KLIS, 1999; LIPKE; OVALLE, 1998; NOBEL; VAN DEN ENDE; KLIS, 2000; NOMBELA; GIL; CHAFFIN, 2006). Alguns patógenos humanos, como Cândida albicans e espécies do gênero Aspergillus, também vêm tendo a constituição de parede celular investigada, que poderá ser utilizada como possível alvo de drogas antifúngicas (GEORGOPAPADAKOU; TKACZ, 1995; POULAIN; JOUAULT, 2004; SHIBATA et al., 1995).
Estudos realizados por Falch et al. (2000) mostram que glucanas $\beta-(1 \rightarrow 3)$ ramificadas possuem efeitos estimulantes para o sistema imune. Entretanto os mecanismos celulares pelos quais estas substâncias agem não estão muito bem definidos, sendo a principal hipótese a existência de receptores específicos para estas glucanas nas superfícies das células (MUELLER et al., 2000).

Fatores físico-químicos podem influenciar no efeito destes polissacarídeos sobre o organismo, dentre eles o grau de ramificação, a massa molecular e a conformação apresentada pelo material (LEUNG et al., 2006; YOUNG; JACOBS, 1998). Para compreender os mecanismos de atuação dessas moléculas biológicas todos os parâmetros de caracterização química e conformação devem ser estudados.

Portanto, esta revisão tem como principal objetivo apresentar dados de pesquisas referentes à caracterização química dos polissacarídeos de parede celular fúngica, fornecendo material inicial para investigação nessa área de conhecimento.

\section{Biomassa fúngica}

Os fungos são microrganismos eucariontes heterotróficos que obtêm sua energia pela ruptura de moléculas orgânicas, podendo ocupar diversos nichos ecológicos, atuando como parasitas, sapróbios ou então estabelecendo relações simbióticas, por exemplo, com algas, formando os líquens (TORTORA; FUNKE; CASE, 2000).

No ambiente terrestre, os fungos têm um papel importante nos ciclos biogeoquímicos do carbono, nitrogênio ou fósforo (BOSWELL et al., 2003). Como fitopatógenos, estes organismos possuem 
mecanismos de adesão ao hospedereiro, onde as moléculas de reconhecimento e união são, na maior parte dos casos, de natureza protéica ou glicoprotéica (SUGUI; LEITE; NICHOLSON, 1998; XIAO et al., 1994) e, por isso, a produção de proteínas e polissacarídeos extracelulares têm sido associadas à capacidade do microrganismo causar doenças em plantas (DOSS, 1999; GIL-AD; BARNUN; MAYER, 2001; LEITE et al., 2001).

Os fungos podem ser considerados como os agentes mais importantes de degradação da Terra, principalmente quando se estuda os ecossistemas florestais, onde esses microrganismos são os principais decompositores de celulose e lignina. A produção de biomassa em um ecossistema florestal é em grande parte controlado por fungos degradadores de madeira, que determinam as taxas dos nutrientes liberados e seu retorno ao ecossistema após a morte das árvores (ESPOSITO; AZEVEDO, 2004)

Além de sua atuação nos ecossistemas, os fungos tambémapresentamum grande potencial de aplicação nas diferentes áreas industriais, como alimentos, cosméticos, medicamentos(SUTHERLAND, 1998), assim como na área ambiental, na detoxificação de compostos em ambientes contaminados (REZENDE et al., 2005). A utilização desses microrganismos pode ser através do seu material celular (biomassa) ou então de macromoléculas isoladas.

Há uma forte tendência em se explorar comercialmente a biomassa fúngica para isolamento de seus componentes celulares e consequentemente de seus principais constituintes, tais como enzimas (invertases, glucosidades), nucleotídeos, proteínas (manoproteínas) e principalmente polissacarídeos (glucanas, mananas, galactanas), além de lipídeos, como fosfolipídeos eergosterol, poisestas substâncias apresentam propriedades específicas de interesse biotecnológico e, conseqüentemente, de grande valor agregado (BELEM; LEE, 1998; BEROVIČ et al., 2003; CAMERON; COOPER; NEUFELD, 1988; KOLLÁR; STURDIK; SAJBIDOR, 1992; PAVLOVA, PANCHEV; HRISTOZOVA, 2005).
Trabalhos como os realizados por Mendes-Costa e Moraes (1999) mostraram que é possível isolar da biomassa de diferentes linhagens de Saccharomyces cerevisiae frações de carboidratos solúveis, e que estas moléculas podem ser utilizadas como indutoras de mecanismos de defesa em plantas. $\mathrm{O}$ mesmo foi observado em experimentos com soja (HAHN; ALBERSHEIM, 1978; SHARP; VALENT; ALBERSHEIM, 1984), feijão, batata (CLINE, WADE, ALBERSHEIN, 1978) e sorgo (PICCININ; DI PIERO; PASCHOLATI, 2005), onde se detectou a produção de fitoalexinas, substâncias envolvidas no mecanismo de defesa vegetal, quando as plantas foram colocadas em contato com glucanas isoladas de S. cerevisiae e de Phytophtora megasperma.

A biomassa excedente da produção industrial de antibióticos por Penicillium chrysogenum, além de ser aproveitada para ração para gado e ou no preparo de fertilizantes (MUZZARELLI et al., 2000), também vem se mostrando uma fonte viável de moléculas importantes, como os polissacarídeos do tipo glucanas (WANG et al., 2007), aplicados na área medicinal devido a suas atividades antitumorais e imunomoduladoras.

Durante um processo fermentativo para a produção de exopolissacarídeos (EPS), um grande percentual de biomassa também é obtido. Entretanto, as quantidades de massa micelial e EPS não são necessariamente proporcionais, sendo dependentes dos diferentes fatores utilizados no cultivo, tais como fontes de carbono e de nitrogênio, $\mathrm{pH}$, temperatura, agitação, grau de aeração, entre outros. Estes parâmetros podem interferir tanto na produção da biomassa quanto dos componentes isolados desse substrato. Segundo alguns autores (BARBOSA et al., 2004; SELBMANN; CROGNALE; PETRUCCIOLI, 2002; SEVIOUR et al., 1992; WANG; McNEILL, 1995) o resultado esperado no final do procedimento, se biomassa ou EPS, determinará como essas variáveis serão aplicadas no cultivo microbiano.

A influência desses parâmetros pode ser ilustrada, 
por exemplo, por Park et al. (2002), que trabalhando com Cordyceps militaris para a produção de exopolissacarídeos, observaram que o aumento da taxa de aeração favorecia a produção de biomassa em relação à de macromoléculas extracelulares. Tang e Zhong (2003) mostraram que variações nos níveis de saturação de oxigênio em cultivos de Ganoderma lucidium influenciavam o fornecimento de oxigênio, levando a produção de quantidades diferentes de polissacarídeos intracelulares, extracelulares e de ácido ganodérico pelo fungo. Os pesquisadores observaram que uma menor saturação de oxigênio (10 \%) favorecia a produção de polissacarídeo extracelular $(0,7 \mathrm{~g} / \mathrm{L})$, enquanto que com um grau de saturação de oxigênio maior (25\%) havia um aumento de polissacarídeos intracelulares $(1,6 \mathrm{~g} / \mathrm{L})$ e de ácido ganodérico $(350 \mathrm{mg} / \mathrm{L})$.

Portanto, pode-se concluir que valores significativos de biomassa podem ser obtidos por otimização de condições de cultivo, e que isso permite um aumento nas quantidades de componentes celulares que podem ser extraídos e terem suas moléculas básicas investigadas, para posteriores aplicações industriais e ou ambientais.

\section{Parede celular fúngica}

Nos fungos, a estrutura celular é semelhante a dos outros eucariotos, constituída basicamente por uma membrana, um citoplasma com as organelas distribuídas aleatoriamente por todo interior celular e um compartimento especial, o núcleo, que armazena o material genético. As células podem ser encontradas na forma unicelular, como as leveduras, ou então formando conjuntos de hifas, septadas ou não, denominadas de micélio, como no caso dos fungos filamentosos. Tanto as células leveduriformes quanto o micélio estão envolvidos por uma camada protetora externa denominada de parede celular, quimicamente diferente da parede encontrada em vegetais, ainda que possa exercer os mesmos tipos de funções (JUNQUEIRA; CARNEIRO, 2005; MADIGAN; MARTINKO; PARKER, 2004).
A parede celular fúngica pode ser caracterizada como uma estrutura relativamente rígida, porém dinâmica, que participa de vários processos biológicos essenciais à célula. Ela determina o formato da célula, fornece suporte osmótico, proteção física, além de estar relacionada a eventos de sinalização celular, adesão e reprodução (MAGNELLI; CIPOLLO; ROBBINS, 2005; NIMRICHTER et al., 2005; PEREZ; RIBAS, 2004), sendo por isso necessária para o crescimento e desenvolvimento dos fungos nos ambientes onde são encontrados (DURAN; NOMBELA, 2004).

O crescimento micelial é dependente do processo de translocação, onde o material celularé direcionado para as regiões em desenvolvimento (BOSWELL et al., 2003), permitindo a formação das estruturas celulares, como a parede, e com isso facilitando a ocupação dos ambientes pelo microrganismo. Em condições normais de desenvolvimento, a estrutura da parede celular é baseada na parede já existente nas células progenitoras, que são extendidas e remodeladas. Neste caso, ela serve como um arcabouço para a incorporação de novos materiais dentro dos pontos de crescimento (KLIS; BOORSMA; DE GROOT, 2006).

A parede celular compreende cerca de 20$30 \%$ do peso seco da célula fúngica (SMITH et al., 1999); sua composição química, estrutura e dimensão variam consideravelmente, dependendo das condições ambientais e/ou de cultivo laboratorial e essa formação é coordenada com o ciclo celular (KLIS; BOORSMA; DE GROOT, 2006).

A composição química da parede celular é bastante complexa, constituída principalmente por polissacarídeos, ligados ou não a proteínas ou lipídeos, polifosfatos e íons inorgânicos formando a matriz de cimentação. Quitina, glucanas, galactomananas e proteínas são compostos mais freqüentes, embora sua quantidade varie entre as diferentes espécies de fungos (ADAMS, 2004).

O conhecimento da constituição química da parede, principalmente em relação à presença 
de polissacarídeos, é um dado importante para o emprego biotecnológico dos fungos, pois estas moléculas podem ser utilizadas em diversos processos industriais ou, ainda, serem úteis para a classificação taxonômica desses organismos (MADIGAN; MARTINKO; PARKER, 2004).

Vários estudos têm sido realizados para o conhecimento da composição química da parede celular de fungos, principalmente leveduras, como Schizosaccharomyces pombe e Saccharomyces cerevisiae,muitoutilizadasemindústriasdealimentos (DURAN; NOMBELA, 2004; GALICHET et al., 2001; KIM; YUN, 2005; MAGNELLI; CIPOLLO; ROBBINS, 2005; NOMBELA; GIL; CHAFFIN, 2006).

De acordo com Aguilar-Uscanga e François (2003) a parede celular de leveduras apresenta como componentes polímeros de manose (constituindo manoproteínas), glicanas (principalmente betaglucanas, mas galactanas também podem ser encontradas) e polímeros de $\mathrm{N}$-acetilglucosamina (formando quitina).

Cerca de 60 a $90 \%$ do peso seco da parede celular de $S$. cerevisiae é constituída de glucanas e mananas (CHAUD; SGARBIERI, 2006). Para Kapteyn, Van Den Ende e Klis (1999), a parede celular desta levedura é organizada em duas camadas formadas por quatro classes de macromoléculas como proteínas de parede celular (CWPs), $\beta-(1 \rightarrow 6)$-Dglucana, $\beta-(1 \rightarrow 3)$-D-glucana e quitina, com estes componentes interconectados através de ligações covalentes.

Lipke e Ovalle (1998) através de estudos realizados com microscopia eletrônica observaram a disposição em camadas dos polissacarídeos da parede celular de S. cerevisiae. Acamada mais interna é constituída principalmente por uma $\beta$ - $(1 \rightarrow 3)$-Dglucana com pequeno grau de substituição em C-6 por resíduos glucopiranosídicos, que variavam em relação ao grau de maturação da célula. Segundo esses autores, a glucana poderia ser solúvel ou insolúvel, em solução aquosa, dependendo do percentual de ramificação. Os demais constituintes da camada interna observados foram a quitina, presente em proporções reduzidas nas regiões de cicatrizes de brotamento, e uma $\beta$ - $(1 \rightarrow 6)$-D-glucana altamente ramificada, solúvel em água (KLIS et al., 2002). Finalmente, uma manana constituída de uma cadeia principal de $\alpha$ - $(1 \rightarrow 6)$-D-manopiranose altamente ramificada também foi descrita como constituinte da parede celular em $S$. cerevisiae. As ramificações foram caracterizadas como cadeias laterais de comprimentos variados de unidades de manose $\alpha-(1 \rightarrow 2)$ e em menor proporção $\alpha-(1 \rightarrow 3)$ ligadas, distribuídas de forma complexa ao longo da cadeia principal (KAPTEIN; VAN DEN ENDE; KLIS, 1999).

A levedura Schizosaccharomyces pombe, espécie considerada modelo para o estudo da relação entre a formação da parede celular e o ciclo celular, também apresenta $\beta$ - $(1 \rightarrow 3)$ glucana com ramificação em C-6 (MAGNELLI; CIPOLLO; ROBBINS, 2005). Uma característica distinta desta levedura é a ausência de quitina, um polissacarídeo geralmente presente em outros fungos. Foram identificados outros polissacarídeos como uma $\alpha-(1 \rightarrow 3)$ glucana e uma galactomanana típica de leveduras, formada por uma cadeia principal de $\alpha-(1 \rightarrow 2)$ manopiranose, com unidades de galactose substituindo as posições terminais (PÉREZ; RIBAS, 2004).

A parede celular dos fungos Candida albicans e Aspergillus fumigatus, responsáveis por doenças em humanos, apresenta componentes como manana (Candida), galactomanana (Aspergillus) e $\beta-(1 \rightarrow 3)$ D-glucana (ambos microrganismos) que podem ser utilizados para o diagnóstico de infecções fúngicas invasivas, pois estas moléculas, consideradas como antígenos circulantes, são detectados no sangue em uma fase inicial da infecção e antes do surgimento dos sintomas clínicos. A detecção desses antígenos é um procedimento mais rápido que os métodos tradicionais, realizados por estudos histológicos ou cultura de células. A presença desses antígenos também pode ser utilizada para monitorar a resposta dos pacientes ao tratamento com agentes antifúngicos (ERJAVEČ; VERWEIJ, 2002). 
Como a parede celular é essencial para a sobrevivência da célula fúngica e está ausente em células de mamíferos, ela se torna um alvo atrativo para a ação de drogas. Portanto, o conhecimento da síntese da parede celular, bem como de sua composição química podem dar informações valiosas para aplicação desses agentes antifúngicos (PEREZ; RIBAS, 2004).

\section{Polissacarídeos de parede celular fúngica}

Os polissacarídeos sãoumaclassedebiopolímeros produzidos por todos os organismos vivos. Eles exibem diferentes tipos de estruturas químicas, funções fisiológicas e aplicações (ZOHURIAAN; SHOKROLAHI, 2004). Estas moléculas são polímeros de monossacarídeos unidos por ligações glicosídicas, formadas a partir da eliminação de uma molécula de água entre o grupo hidroxila hemiacetal de um resíduo e um grupo hidroxila primário ou secundário de outro resíduo adjacente. Podem ser constituídos por números variáveis de resíduos em uma estrutura linear, ramificada ou ocasionalmente cíclica e sua massa molecular pode variar de milhares a milhões de daltons (PAZUR, 1994).

Nos organismos vivos, os polissacarídeos podem estar sozinhos ou covalentemente combinados com outros compostos de diferentes classes biológicas, principalmente proteínas e lipídeos, constituindo os glicoconjugados. Em combinação ou livres, essas moléculas têm importantes funções biológicas (NELSON; COX, 2002).

Em microrganismos, os polissacarídeos podem ser estruturais, excretados ao meio como exopolissacarídeos (EPS) ou localizarem-se no citoplasma, exercendo a função de reserva energética (KRCMAR et al., 1999; NELSON; COX, 2002). Os polissacarídeos microbianos têm recebido considerável atenção devido ao seu potencial de aplicação em diferentes áreas industriais incluindo cosméticos e alimentos funcionais, além de medicamentos (BAIS et al., 2005; FRANÇOIS;
ROJAS; DARAIO, 2005; METHACANON et al., 2005; VANDAMME et al., 2002).

Nos fungos, os polissacarídeos constituem um percentual importante da biomassa, onde a parede da hifa é formada por mais de $75 \%$ dessas moléculas, principalmente em basidiomicetos. Além de atuarem como um suporte para a hifa, essas macromoléculas também podem constituir uma "capa" extracelular ao redor do micélio (GUTIÉRREZ; PRIETO; MARTINEZ, 1996).

A composição e estrutura química dos polissacarídeos de parede celular são variáveis entre as diferentes espécies de microrganismos. Com base nos resultados provenientes da caracterização química dessas macromoléculas, alguns autores propõem a sua utilização como marcadores para a classificação taxonômica de fungos filamentosos, leveduras e liquens (CARBONERO et al., 2003, 2005; GORIN; SPENCER, 1970; PESSONI et al., 2005; TEIXEIRA; IACOMINI; GORIN, 1995).

Considerando-se o grande número de fungos encontrados na natureza e a possibilidade de terem em sua composição endo- e exopolissacarídeos com diferentes aplicações medicinais, estudos estão sendo realizados para verificar o potencial dessas macromoléculas como antioxidantes, antimutagênicos, anticoagulantes, antitrombóticos e imunomoduladores (FREIMUND et al., 2003; CORRADI DA SILVA et al., 2006; ZHANG et al., 2005).

Dentre os polissacarídeos encontrados na parede celular fúngica as glucanas são os homopolissacarídeos mais comuns. A maioria é linear, com diferentes disposições de suas ligações glicosídicas, pertencentes à série alfa $(\alpha)$ ou beta $(\beta)$. As $\beta$-glucanas são a forma predominante, podendo estar livres ou associadas às proteínas, lipídeos e outros polissacarídeos. A conformação destas moléculas pode variar desde simples até tripla hélice, que é a forma mais comum, onde três cadeias de polímeros são agregadas por ligações de hidrogênio nos oxigênios do C-2 (WILLIAMS, 1997). 
As $\beta$ - $(1 \rightarrow 3)$-D-glucanas encontradas em extratos celulares de Saccharomyces cerevisiae possuem ramificações em C-6 e esses terminais não redutores podem estar covalentemente ligados à cadeia de quitina através de ligação $\alpha-(1 \rightarrow 4)$ (LESAGE; BUSSEY, 2006).

A síntese de $\beta$-glucanas em fungos envolve várias etapas: reações de iniciação, alongamento da cadeia e ramificação, das quais a mais estudada é o alongamento da cadeia que envolve a reação catalisada pela enzima glucana $\beta-(1 \rightarrow 3)$ sintetase a partir de uridina difosfato-glucose (UDP-glucose) como substrato (RUIZ-HERRERA, 1991). De acordo com Douglas (2001), a polimerização dos açúcares é gradativa, sendo adicionada uma unidade de glucose por vez, até se formar as longas cadeias.

$\mathrm{Na}$ parede celular de algumas leveduras, como Cândida dubliniensis, foi encontrado um componente majoritário rico em manose associado a uma proteína, constituindo as manoproteínas. A esse tipo de glicoconjugado têm sido atribuídas funções de adesão entre células, habilidades imunomoduladores e variabilidade antigênica (LIŽIČÁROVÁ et al., 2007). Moléculas de manose podem também, ser encontradas em galactomananas, que são heteropolissacarídeos constituídos por uma cadeia principal de manose ligada a resíduos de galactose, presentes em espécies do gênero Aspergillus, como A. fumigatus e A. wentii, e Chaetosartorya chrysella, fungos estudados em relação à patogenicidade humana (GÓMEZMIRANDA et al., 2004). Dependendo do grau de ramificação, bem como do tamanho da cadeia lateral, as galactomananas apresentam propriedades físicas e químicas distintas, que permitem classificálas como uma família de macromoléculas.

Um constituinte menor da parede celular e comum em fungos é a quitina, um homopolímero linear, longo, formado por resíduos de $\mathrm{N}$-acetilglucosamina $\beta-(1 \rightarrow 4)$ ligados. Compreende cerca de 1 a $2 \%$ da parede celular de leveduras embora seja encontrada em maior proporção (10 a 20\%) em fungos filamentosos. Pontes de hidrogênio intercadeia dão origem a microfibrilas de quitina. Essas estruturas suportam grandes pressões e, portanto, tornam-se responsáveis pela integridade da parede celular. Quando a síntese da quitina é interrompida, a parede celular torna-se desorganizada e a célula fúngica sofre deformações e instabilidade osmótica (BOWMANN; FREE, 2006).

A caracterização química dos constituintes da parede celular fúngica contribuirá para o conhecimento básico do microrganismo, para o entendimento de suas relações com o meio e a provável utilização biotecnológica de seus componentes isolados.

\section{Procedimentos gerais para purificação e caracterização de polissacarídeos de parede celular}

Visto que a biomassa fúngica constitui uma valiosa fonte de proteínas, lipídeos e principalmente de polissacarídeos que apresentam inúmeras propriedades benéficas para a saúde humana, animal e vegetal, diferentes métodos são utilizados para o isolamento e caracterização destes polissacarídeos.

Primeiramente, é necessário efetuar a extração eficiente dos polissacarídeos evitando, tanto quanto possível, reações de degradação. Os procedimentos mais comuns são as extrações aquosas a frio, a quente e/ ou alcalina, com $\mathrm{NaOH}$ ou $\mathrm{KOH}$, ou até mesmo com auxílio de enzimas específicas. Os extratos obtidos, geralmente são constituídos por uma mistura de polissacarídeos (PÉREZ; RIBAS, 2004).

Precedendo a caracterização (PAZUR, 1994), procedimentos de purificação devem ser efetuados até que a composição monossacarídica da macromolécula em estudo se mantenha constante por, pelo menos, dois métodos diferentes. Normalmente, métodos cromatográficos e/ou químicos dão informações em relação à pureza da preparação polissacarídica (BOYER, 1993; DANISHEFSKY; WHISTLER; BETTELHEIM, 1970). 
Considerando-se a pureza do material o primeiro procedimento químico para conhecer a composição de uma fração rica em carboidrato é fragmentála, visando obter os resíduos monossacarídicos que a constitui (NELSON; COX, 2002). Esta fragmentação pode ser realizada através de hidrólises enzimática ou ácida. Estabelecidas às condições ideais de hidrólise, a identificação dos monômeros passa a ser a etapa seguinte da análise. Os métodos cromatográficos são os mais utilizados e a cromatografia líquida de alta pressão em troca aniônica (HPAEC) tem sido, juntamente com a cromatografia gasosa, os de preferência (RUASMADIEDO; LOS REYES-GAVILAN, 2005).

O tipo de ligação glicosídica geralmente é determinado após a análise dos acetatos de alditóis parcialmente metilados por cromatografia gasosa e espectrometria de massa (cg/em) e a configuração anomérica dos monossacarídeos que constituem a macromolécula por FT-IR (MOHAČEK-GROŠEV; BOŽAC; PUPPELS, 2001; SILVERSTEIN, 1994) e RMN de ${ }^{13} \mathrm{C}$ (GORIN, 1981; SILVA et al., 2006) 1981).

\section{Polissacarídeos de parede celular fúngica: purificação e caracterização}

Estudos demonstram que os polissacarídeos fúngicos podem ser isolados da parede celular do corpo de frutificação, do micélio, do esclerócio (forma de resistência) ou então serem provenientes de meios de cultivo livres de células (extracelulares) (MONDAL et al., 2004; SILVA et al., 2006; WANG et al., 2004).

Vários polissacarídeos foram isolados da parede celular do Phytophthora parasitica, um fungo fitopatogênico. A mistura polissacarídica foi fracionada por cromatografias sucessivas em DEAE-celulose, Sephadex G-25, Concanavalina-A Sepharose e Sephadex G-200. Os polissacarídeos neutros consistiam de uma $\beta$-D-glucana $(1 \rightarrow 3,1 \rightarrow 6)$ cuja massa molecular ficou entre $9 \times 10^{3}$ a $200 \times 10^{3}$ Da. Todos estes polissacarídeos eram constituídos por uma cadeia principal de resíduos de glucose $\beta$ - $(1 \rightarrow 3)$ ligados (FABRE et al., 1984).

O principal componente encontrado no extrato aquoso do corpo de frutificação de Boletus erythropus foi uma $\beta$-glucana contendo resíduos de glucose com ligações $(1 \rightarrow 3)$, sendo substituídas em $O-6$ por terminais não redutores de -D-Glc $p$, na freqüência de 1:3 (CHAUVEAU et al., 1996).

Ruiz-Herrera et al. (1996) mostraram que as composições monossacarídicas do micélio e da levedura de Ustilago maydis, um hemibasidiomiceto fitopatogênico que causa doença em milho, são distintas. Glucose $(41 \%)$, galactose $(32 \%)$, manose $(16 \%)$ e xilose (11\%), monossacarídeos encontrados na forma micelial diferiram daqueles encontrados na forma leveduriforme: glucose $(26 \%)$, xilose $(23 \%)$, manose $(23 \%)$, galactose $(11 \%)$, fucose $(6 \%)$, arabinose $(6 \%)$ e ribose $(5 \%)$.

Prieto et al. (1997) isolaram um polissacarídeo complexo, por extração alcalina, da parede celular dos fungos Trichoderma reesei, T. koningii (forma teleomórfica)e Hypocrea psychrophila (anamórfica). Esses fungos, encontrados no solo, têm grande importância econômica por atuarem como agentes de biocontrole de fungos fitopatogênicos e por serem produtores de enzimas como as celulases. Após hidrólise ácida do polissacarídeo complexo solúvel em água foram detectados por cromatografia gasosa, como acetato de alditóis, os açúcares glucose, galactose e manose. Análises de metilação e ressonância magnética nuclear de carbono 13 e próton uni- e bidimensional mostraram um estrutura altamente complexa com uma cadeia principal constituída de unidades manopiranosídicas $\alpha-(1 \rightarrow 6)$ ligadas, algumas unidades substituídas em 2 por oligossacarídeos com unidades galactofuranosídicas alternadas com ácido glucurônico ou em 3 por unidades $\alpha$ manopiranosídicas.

Ahrazem et al. (1997) caracterizaram um polissacarídeo acídico isolado da parede celular de Cylindrocladium e de sua forma anamórfica Calonectria, por extração alcalina. Os acetatos 
de alditóis, galactose, glucose e manose foram detectados por cromatografia gasosa, além da presença de ácido urônico. Análises de metilação mostraram os derivados 2,3,4,6-tetra-O-metil glucitol e 3-5-di-O-metil galacitol, além de 5\% de 2,3,4-tri-O-metil manitol, e 3,4-di-O-metil manitol. $\mathrm{O}$ espectro de $\mathrm{RMN}$ de ${ }^{13} \mathrm{C}$ mostrou apenas dois sinais na região anomérica, $\delta 107,1$ ppm e 176,2 ppm, atribuídos, respectivamente, aos resíduos $\beta$-galactofuranosídicos e carbonila, confirmando a presença de ácido urônico.

Uma $\beta$-D-glucana- $(1 \rightarrow 3)$ solúvel substituída em C-6, em uma proporção de aproximadamente $30 \%$, foi encontrada como principal componente da extração alcalina da parede celular de Cryphonectria parasítica (MOLINARO et al., 2000).

Zhang et al. (2000) extraíram uma glucana do corpo de frutificação do basidiomiceto Ganoderma lucidum. Após resultados das análises de metilação, oxidação pelo periodato, ressonância magnética nuclear de carbono 13 e espectroscopia de infravermelho, a molécula foi caracterizada como um polímero linear constituído de resíduos glucosídicos $\alpha-(1 \rightarrow 3)$ ligados.

Um polissacarídeo solúvel foi isolado do extrato aquoso a quente do corpo de frutificação de Agaricus blazei (Murr) por precipitação etanólica, cromatografia de trôca-iônica e cromatografia de filtração em gel.As análises de metilação, degradação de Smith, hidrólise branda e espectroscopia de $\mathrm{RMN}$ de ${ }^{13} \mathrm{C}$ mostraram que o polissacarídeo era composto por uma cadeia principal de resíduos glucosídicos em ligação $\beta$ - $(1 \rightarrow 6)$, substituídos em C-3 por resíduos laminaribiosídicos (DONG et al., 2002).

O corpo de frutificação de Ganoderma lucidum, tem sido usado tradicionalmente na medicina chinesa e em outros países asiáticos por apresentarem efeitos medicinais contra câncer, hipertensão, hepatite e hipercolesterolemia e vários polissacarídeos têm sido obtidos a partir do extrato aquoso dessa estrutura de Ganoderma (BAO et al., 2002a).
Uma das glucanas isoladas foi caracterizada como tendo uma cadeia principal constituída de unidades glucopiranosídicas $\beta-(1 \rightarrow 3)$ substituídas em $O-6$ por uma unidade de glucose (BAO et al., 2002a; BAO; FANG; LI, 2001). Glucanas com estrutura química semelhantes também foram isoladas dos esporos deste mesmo fungo (BAO et al., 2002b).

Domenech et al. (2002) isolaram e caracterizaram uma galactomanana do extrato alcalino da parede celular de três linhagens de Verticillium fungicola, considerado um dos patógenos mais comuns no cultivo do cogumelo Agaricus biosporus. A fração F1SS, das três linhagens estudadas, era constituída por manose e galactose. A análise de metilação mostrou dois picos identificados como 1,5-di-O-acetil-2,3,4,6-tetra-O-metil-galacitol, que correspondem a galactopiranose, e 1,4,5,6-tetraO-acetil-2,3-di-O-metil-manitol e um pequeno percentual de Man $p$ 6-O-substituído. A massa molecular média dos polissacarídeos, determinada por cromatografia de filtração em gel de Sepharose CL-6B, ficou entre 70 a $80 \mathrm{kDa}$. Os resultados da análise de metilação juntamente com espectros de $\mathrm{RMN}$ de $\mathrm{H}^{1}$ e de $^{13} \mathrm{C}^{1}$ sugeriram uma estrutura formada por uma cadeia principal de unidades manopiranosídicas $\alpha-(1 \rightarrow 6)$ ligadas e substituídas em $O-4$ por resíduo $\beta$-D-galactopiranosídicos. Esses resultados confirmam a semelhança estrutural dos polissacarídeos nas diferentes linhagens e reforçam a aplicação dos polissacarídeos como marcadores taxonômicos.

Ahrazem et al. (2002) caracterizaram um polissacarídeo solúvel em água, extraída com álcali de paredes celulares das espécies de Geotrichum spp. (forma anamórfica), Galactomyces e Dipodascus (formas teleomóficas). Por análise de metilação e ressonância magnética nuclear concluíram que o polissacarídeo era uma galactomanana com cadeia principal constituída de unidades $\alpha$-D-man $p$ $1 \rightarrow 6$ e substituídas em 2 por $(\alpha-\mathrm{D}-\mathrm{Gal} p-(1 \rightarrow 2)$ $\alpha$-D-Man $p-1 \rightarrow)$. Todas as espécies estudadas apresentaram o mesmo polissacarídeo e, portanto, concluíram tratar-se do mesmo gênero. 
Uma linhagem selvagem de Poria cocos foi cultivada, separadamente, em extrato de cevada e em extrato fermentado de milho e denominadas de wb e wc, respectivamente. Seis frações polissacarídeos foram isoladas, seqüencialmente, dos dois micélios por extrações com $\mathrm{NaCl}$ 0,9\% (PCM1), aquosa a quente (PCM2), $\mathrm{NaOH}$ 0,5M (PCM3-I e-II) e ácido fórmico a $88 \%$ (PCM-4-I e -II). Glucanas extraídas com $\mathrm{NaOH} 0,5 \mathrm{M}$ se separam em duas frações, denominadas PCM3-I e PCM3-II, após neutralização com ácido acético. As características físicas e químicas foram determinadas por espectroscopia de IV (Infra-Vermelho), cromatografia gasosa (CG), $\mathrm{RMN}-{ }^{13} \mathrm{C}$, light scattering (LS) e viscosimetria. Os resultados indicaram que as frações PCM-1 e PCM-2 dos cultivos em wb e wc eram constituídas por heteropolissacarídeos formados por glucose, manose e galactose, enquanto que em PCM3-I foram encontradas glucanas lineares com ligações do tipo $\alpha-(1 \rightarrow 3)$. As frações PCM3-II, PCM4-I e PCM4-II eram compostas de glucanas lineares com ligações do tipo $\beta$-( $1 \rightarrow 3$ ) (JIN et al., 2003).

Jia et al. (2004) elucidaram a estrutura de um heteropolissacarídeo de peso molecular de $1,8 \times 10^{4}$ $\mathrm{Da}$, composto por ramnose, glucose e galactose na proporção de 1,19: 3,81: 1,00, isolado do corpo de frutificação do fungo medicinal chinês Hericium erinaceus. Suas características estruturais foram investigadas utilizando análise de metilação, hidrólise parcial, espectroscopia de infravermelho e de RMN. Os resultados mostraram que a cadeia principal era formada por unidades $\alpha$-Dgalactopiranosídicas com ramificações em $O-2$ por resíduos de ramnose e glucose.

Chakraborty et al. (2004) isolaram e caracterizaram uma heteroglucana da extração aquosa a quente $\left(100^{\circ} \mathrm{C}, 6 \mathrm{~h}\right)$ do corpo de frutificação do fungo comestível Astraeus hygrometricus que constitui micorrizas crescendo junto com as raízes de árvores auxiliando na extração de nutrientes, especialmente o fósforo do solo, e de substâncias orgânicas. A fração solúvel do extrato aquoso foi investigada e os resultados das análises de hidrólise ácida total, metilação e RMN permitiram concluir que se tratava de uma glucana com ligações glicosídicas do tipo $\alpha-(1 \rightarrow 4)$ e $\beta-(1 \rightarrow 6)$.

Mondal et al. (2004) realizaram uma extração aquosa do corpo de frutificação $\left(100^{\circ} \mathrm{C}, 6 \mathrm{~h}\right)$ de Termitomyces eurhizus, um cogumelo de grande interesse devido a suas propriedades imunomoduladora e seu alto valor nutritivo. O extrato deste microrganismo, depois de dializado e precipitado com etanol, foi submetido à purificação pela cromatografia de filtração em gel Sephadex G-50 onde foram separadas duas frações homogêneas, denominadas PS-I e PS-II. Análises de metilação, oxidação com periodato, $\mathrm{RMN}$ do ${ }^{13} \mathrm{C}$ e de ${ }^{1} \mathrm{H}$, mostraram que o polissacarídeo da fração PS-I era composto por unidades glucopiranosídicas unidas por ligações do tipo $\alpha-(1 \rightarrow 3)$ e $\alpha-(1 \rightarrow 6)$ na proporção de 2,5:1. PS-II também era um polímero de glucose mas com ligações do tipo $\alpha-(1 \rightarrow 6)$.

Uma glucana isolada do micélio de um fungo comestível chinês Cordyceps sinensis foi caracterizada por análise de metilação, degradação de Smith, acetólise, espectroscopia de NMR $(1 \mathrm{H}, 13 \mathrm{C}, 13 \mathrm{C}-1 \mathrm{H}$ 2D-COSY) e hidrólise ácida total. Os resultados mostraram que cadeia principal era composta de resíduos $\alpha-(1 \rightarrow 4)$-Dglucopiranosídicos ligados a um único resíduo $\alpha$-(1 $\rightarrow 6)$-D-glucosídicos (YALIN; CUIRONG; YUANJIANG, 2006).

Um endopolissacarídeo foi isolado do extrato aquoso a quente do micélio do Inonotus obliquus, (fungo de degradação branca) e purificado por cromatografia de troca iônica e de filtração em gel. Após caracterização, o polissacarídeo mostrouse constituído por resíduos de fucose, glucose e manose e massa molecular de aproximadamente $1 \times$ $10^{6} \mathrm{Da}$. Verificou-se que esse endopolissacarídeo é um ativador específico de células $\mathrm{B}$ e de macrófagos. Os resultados in vivo e in vitro comprovaram que a atividade antitumoral não se deve ao efeito tumoricida e sim ao efeito imunomodulador (KIM et al., 2006). 
Umpolissacarídeoinsolúvelemáguafoiisoladoda extração alcalina $(\mathrm{NaOH})$ do micélio de Penicillium chrysogenum. O peso molecular desse polímero, $180 \mathrm{KDa}$, foi determinado por cromatografia de permeação em gel. Após hidrólise ácida total e análise dos derivados acetilados por cromatografia líquido-gasosa (GLC) foram encontrados os açúcares glucose, manose e galactose nas proporções 98,7: 0,6: 0,7. O espectro de FT-IR apresentou picos de absorção em 929, 846 e $820 \mathrm{~cm}^{-1}$ característicos de glucanas com ligações do tipo $\alpha-(1 \rightarrow 3)$. O espectro de ressonância magnética nuclear de carbono 13 apresentou 6 sinais de intensidades semelhantes. Os deslocamentos químicos em 101,20 ppm e 83,66 ppm foram atribuídos ao carbono anomérico dos resíduos de glucose e ao C-3-O-substituído, respectivamente (WANG et al., 2007).

\section{Atividades biológicas dos polissacarídeos de parede celular fúngica}

Os biopolímeros, de maneira geral, têm sido objetos de pesquisas devido ao seu potencial de aplicação. Estudos realizados com os polissacarídeos da parede celular fúngica demonstram que essas moléculas apresentam uma variedade de respostas biológicas de defesa, mas sua aplicação terapêutica parece estar relacionada com a estrutura química e a conformação espacial de cada macromolécula, sendo que pequenas diferenças estruturais entre polímeros resultam em características peculiares para novas aplicações biotecnológicas (SILVA et al., 2006).

Diferentes funções biológicas desses polímeros foram analisadas, como hipoglicemiantes, antitrombóticas, antibióticas, atividades anti-tumorais e anti-virais, atuação na diminuição da pressão arterial e na concentração de lipídios sanguíneos, na inibição da ação inflamatória e microbiana (ALQUINI et al., 2004; HWANG et al., 2003; ZHANG et al., 2000, 2007). Estudos com os basidiomicetos Agaricus blazei e Lentinus edodes, utilizados na medicina popular japonesa e chinesa para prevenção e tratamento de doenças, mostraram que essas atividades poderiam estar ligadas aos polissacarídeos presentes nestes fungos (CHEN; SHAO; SU, 2004; DELMANTO et al., 2001; LIMA et al., 2001).

As glucanas são os polissacarídeos mais estudados em relação à atividade biológica. Essas moléculas, principalmente do tipo $\beta$ - $(1 \rightarrow 3)$ e/ou $\beta-(1 \rightarrow 3 ; 1 \rightarrow 6)$, são capazes de ativar células do sistema imunológico humano, como macrófagos, neutrófilos e células NK (natural killer), para a secreção de citocinas (interleucinas, interferon e fator necrosante tumoral) que são substâncias que atuam como sinais químicos nos processos de diferenciação, proliferação e apoptose celulares, contribuindo para a manutenção da homeostase no organismo (ABBAS; LICHTMAN; POBER, 2000; HABIJANIČ et al., 2001).

Muitos medicamentos utilizados em neoplasias apresentam como efeito colateral uma ação imunossupressora, que pode acarretar em infecção e septicemia. Devido à capacidade das $\beta$-glucanas em estimular o sistema imunológico, elas podem ser utilizadas como adjuvantes desses quimioterápicos no tratamento de pacientes imunocomprometidos (BOHN; BeMILLER, 1995; LEE et al., 2001; LEUNG et al., 2006; SUGAWARA et al., 2004; ZHANG et al., 2005).

Além das glucanas, outros polisssacarídeos de parede também estão sendo investigados com o intuito de determinar suas atividades biológicas.

DeacordocomZhangetal.(2007), manoglucanas, galactomananas, e glucomananas, obtidas da biomassa de basidiomicetos, tais como Ganoderma lucidum, Grifola frondosa e diferentes espécies do gênero Pleurotus, como P. cittinopileatus, também podem apresentar atividades antitumorais ou imunomoduladoras.

Martinichen-Herrero et al. (2005) isolaram e caracterizaram uma galactomanana do líquen Cladonia ibitipocae e a modificaram quimicamente pela inserção de grupamentos sulfato, num processo 
denominado sulfatação; os polissacarídeos original e modificado apresentaram atividades anticoagulante e antitrombótica distintas em experimentos realizados em ratos, com os resultados mais positivos relacionados à molécula sulfatada.

Trabalhos realizados por Krizková et al. (2001), investigaram glucomananas isoladas de Candida utilis e mananas de Saccharomyces cerevisiae e Candida albicans Eles observaram que essas moléculas apresentavam atividade antimutagênica, pois eram capazes de reduzir danos oxidativos ao DNA de cloroplastos do flagelado Euglena gracilis, e que esta ação poderia estar relacionada à característica das moléculas em seqüestrar radicais livres, demonstrando também que esses polissacarídeos possuem atividade antioxidante.

Além das funções biológicas destacadas acima, é importante também ressaltar que dependendo das características químicas que esses biopolímeros apresentemcomo, porexemplo,ograudesolubilidade em soluções aquosas, é possível também a sua utilização nos mais diversos segmentos industriais, como indústrias de alimentos, cosméticos, etc (METHACANON et al., 2005; SHAH et al., 2000; SUTHERLAND, 1998; WANG et al., 2004;).

\section{Referências}

ABBAS, A. K.; LICHTMAN, A. H.; POBER, J. S. Cellular and Molecular Immunology. 4. ed. Philadelphia: Saunders, 2000.

ADAMS, D. Fungal cell wall chitinases and glucanases. Microbiology, Reading, v. 150, n. 7, p. 2029-2035, 2004.

AGUILAR-USCANGA, B.; FRANCOIS, J. M. A study of the yeast cell wall composition and structure in response to growth conditions and mode of cultivation. Letters in Applied Microbiology, Oxford, v. 37, n. 3, p. 268-274, 2003.

AHRAZEM, O.; PRIETO, A.; LEAL, J. A.; GÓMEZMIRNADA, B.; DOMENECH, J.; JIMÉNEZBARBERO; J.; BERNABÉ, M. Structural elucidation of acidic fungal polysaccharides isolated from the cell-wall of genera Cylindrocladium and Calonectria. Carbohydrate Research, Amsterdam, v. 303, n. 1, p. 6772, 1997.
AHRAZEM, O.; PRIETO, A.; LEAL, J. A.; JIMÉNEZBARBERO, J. Fungal cell-wall galactomannans isolated from Geotrichum spp. and their teleomorphs, Dipodascus e Galactomyces. Carbohydrate Research, Amsterdam, v. 337, n. 21-23, p. 2347-2351, 2002.

ALQUINI, G.; CARBONERO, E. R.; ROSADO, F. R.; CONSENTINO, C.; IACOMINI, M. Polysaccharides from the fruit bodies of the basidiomycete Laetiporus sulphureus (Bull.: Fr.) Murr. FEMS Microbiology Letters, Amsterdam, v. 230, n. 1, p. 47-52, 2004.

BAIS, D.; LAPASIN, R.; PARTAL, P.; GALLEGOS, C. Rheological characterization of polysaccharide surfactant matrices for cosmetic O/W emulsions. Journal of Colloid and Interface Science, New York, v. 290, n. 2, p. 546-556, 2005.

BAO, X.; FANG, J.; LI, X. Structural characterization and immunomodulating activity of a complex glucan from spores of Ganoderma lucidum. Biosciences of Biotechnology and Biochemistry, Tokyo, v. 65, n. 11, p. 2384-2391, 2001.

BAO,X.;WANG,X.;DONG,Q.;FANG,J.;LI,X.Structural features of immunologically active polysaccharides from Ganoderma lucidum. Phytochemistry, New York, v. 59, n. 2, p. $175-181,2002 \mathrm{a}$.

BAO, X.; ZHEN, Y.; RUAN, L.; FANG, J. Purification, characterization and modification of lymphocytestimuling polyssaccharide from spores of Ganoderma lucidum. Chemical Pharmaceutical Bulletin, Tokyo, v. 50, p. 623-629, 2002 b.

BARBOSA, A. M.; CUNHA, P. D. T.; PIGATTO, M. M.; SILVA, M. L. C. da . Produção e aplicações de exopolissacarídeos fúngicos. Semina: Ciências Exatas e Tecnológicas, Londrina, v. 25, n. 1, p. 29-42, 2004.

BELEM, M. A. F.; LEE, B. H. Production of bioingredients from Kluyveromyces marxianus grown on whey: an alternative. Critical Reviews in Food Science and Nutrition, Cleveland, v. 38, n. 7, p. 565-598, 1998.

BEROVIČ, M.; HABIJANIČ, J.; ZORE, I.; WRABER, B.; HODŽAR, D.; BOH, B.; POHLEVEN, F. Submerged cultivation of Ganoderma lucidum biomass and immunostimulatory effects of fungal polysaccharides. Journal of Biotechnology, Amsterdam, v. 103, n. 1, p. 77-86, 2003.

BOHN, J. A.; BeMILLER, J. N. ( $1 \rightarrow 3)-\beta$-D-Glucans as biological response modifiers: a review of structurefunctional activity relationships. Carbohydrate Polymers, Barking, v. 28, n. 1, p. 3-14, 1995.

BOSWELL, G. P.; JACOBS, H.; DAVIDSON, F. A.; GADD, G. M.; RITZ, K. Growth and Function of Fungal 
Mycelia in Heterogeneous Environments. Bulletin of Mathematical Biology, Elmsford, v. 65, n. 3, p. 447-477, 2003.

BOWMANN, S. M.; FREE, S. J. The structure and synthesis of the fungal cell wall. BioEssays, Cambridge, v. 28 , n. 8, p. 799-808, 2006.

BOYER, R. F. Modern experimental biochemistry. 2. ed. Califórnia: Benjamin/Cumming Publishing Company, 1993.

CAMERON, D. R.; COOPER, D. G.; NEUFELD, R. $\mathrm{J}$. The mannoprotein of Saccharomyces cerevisiae is effective bioemulsifier. Applied and Environmental Microbiology, Washington, v. 54, n. 6, p. 1420-1425, 1988.

CARBONERO, A. R.; MONTAI, A. V.; MELLINGER, C. G.; ELIASARO, S.; SASSAKI, G. L.; GORIN, P. A. J.; IACOMINI, M. Glucans of lichenized fungi: significance for taxonomy of the genera Parmotrema and Rimelia. Phytochemistry, New York, v. 66, n. 8, p. 929934, 2005.

CARBONERO, A. R.; TISCHER, C.A.; COSENTINO, C.; GORIN, P. A. J.; IACOMINI, M. Structural characterization of a galactomannan from the cyanolichen Leptogium azureum. Carbohydrate Polymers, Barking, v. 53, n. 4, p. 469-473, 2003.

CHAKRABORTY, I.; MONDAL, S.; PRAMANIK, M.; ROUT, D.; ISLAM, S. S. Structural investigation of a water-soluble glucan from an edible mushroom, Astraeus hygrometricus. Carbohydrate Research, Amsterdam, v. 339, n. 13, p. 2249-2254, 2004.

CHAUD, S. G.; SGARBIERI, V. C. Propriedades funcionais (tecnológicas) da parede celular de leveduras da fermentação alcoólica e das frações glicana, manana e glicoproteína. Ciência e Tecnologia de Alimentos, Campinas, v. 26, n. 2, p. 369-379, 2006.

CHAUVEAU, C.; TALAGA, P.; WIERUSZESKI, J. M.; STRECKER, G.; CHAVANT, L. A water-soluble $\beta$-Dglucan from Boletus erythropus. Phytochemistry, New York, v. 43, n. 2, p. 413-415, 1996.

CHEN, L.; SHAO, H. J.; SU, Y. B. Coimmunization of Agaricus blazei Murill extract with hepatitis B virus core protein through DNA vaccine enhances cellular and humoral immune responses. International Immunopharmacology, Amsterdam, v. 4, n. 3, p. 403409, 2004.

CLINE, K.; WADE, M.; ALBERSHEIM, P. Host pathogen interaction. XV. Fungal glucans, which elicit phytoalexin accumulation in soybean, also elicit the accumulation of phytoalexin in other plants. Plant Physiology, Minneapolis, v. 62, n. 6, p. 918-921, 1978.
CORRADI DA SILVA, M. L.; MARTINEZ, P. F.; IZELI, N. L.; SILVA, I. R.; VASCONCELOS, A. F. D.; CARDOSO, M. S. Caracterização química de glucanas fúngicas e suas aplicações biotecnológicas. Química Nova, São Paulo, v. 29, n. 1, p. 85-92, 2006.

DANISHEFSKY, I.; WHISTLER, R. L.; BETTELHEIM, F. A. In: PIGMAN, W.; HORTON, D. (Ed.). The Polysaccharides. 2. ed. New York: Academic Press, 1970. v. 2, p. 375-412.

DELMANTO, R. D.; LIMA, P. L. A.; SUGUI, M. M.; EIRA, A. F.; SALVADORI, D. M. F.; SPEIT, G.; RIBEIRO, L. R. Antimutagenic effect of Agaricus blazei Murrill mushroom on the genotoxicity induced by cyclophosphamide. Mutation Research, Amsterdam, v. 496, n. 1-2, p 15-21, 2001.

DOMENECH, J.; PRIETO, A.; GÓMEZ-MIRANDA, B.; LEAL, J. A.; AHRAZEM, O.; JIMÉNEZ-BARBERO, J.; BERNABÉ, M. Structure of fungal polysaccharides isolated from the cell-wall of three strains of Verticillium fungicola. Carbohydrate Polymers, Barking, v. 50, n. 2, p. 209-212, 2002.

DONG, Q.; YAO, J.; YANG, X.-t.; FANG, J-n. Structural characterization of a water-soluble $\beta$-D-glucan from fruiting bodies of Agaricus blazei Murr. Carbohydrate Research, Amsterdam, v. 337, n. 15, p. 1417-1421, 2002.

DOSS, R. P. Composition and Enzymatic Activity of the Extracellular Matrix Secreted by Germlings of Botrytis cinerea. Applied and Environmental Microbiology, Washington, v. 65, n. 2, p. 404-408, 1999.

DOUGLAS, C. M. Fungal $\beta$ - ( $1 \rightarrow 3)$-D-Glucan synthesis. Medical Mycology, Oxford, v. 39, Supl. 1, p. 55-66, 2001.

DURAN, A.; NOMBELA, C. Fungal cell wall biogenesis: building a dynamic interface with the environment. Microbiology, Reading, v. 150, n. 10, p. 3099-3103, 2004.

ERJAVEČ, Z.; VERWEIJ, P. E. Recent progress in the diagnosis of fungal infections in the immunocompromised host. Drug Resistance Updates, Amsterdam, v. 5, n. 1, p. 3-10, 2002.

ESPOSITO, E.; AZEVEDO, J. L. Fungos: uma introdução à biologia, bioquímica e biotecnologia. Caxias do Sul: EDUCS, 2004.

FABRE, I.; BRUNETEAU, M.; RICCI, P.; MICHEL, G. Isolation and structural studies of glucans from Phytophthora parasitica. European Journal of Biochemistry, Berlin, v. 142, n. 1, p. 99-103, 1984. 
FALCH, B. H.; ESPEVIK, T.; RYAN, L.; STOKKE, B. T. The cytokine stimulating activity of $(1 \rightarrow 3)-\beta-D-$ glucans is dependent on the triple helix conformation. Carbohydrate Research, Amsterdam, v. 329, n. 3, p. 587659, 2000.

FRANÇOIS, N. J.; ROJAS, A. M.; DARAIO, M. E. Rheological and drug-release behaviour of a scleroglucan gel matrix at different drug loadings. Polymer International, London, v. 54, n. 12, p. 1613-1619, 2005.

FREIMUND, S.; SAUTER, M.; KÄPPELI, O.; DUTLER, H. A. New non - degrading isolation process for $1,3-\beta$-Dglucan of hight purity from baker's yeast Saccharomyces cerevisiae. Carbohydrate Polymers, Barking, v. 54, n. 2, p. 159-171, 2003.

GALICHET, A.; SOCKALINGUM, G. D.; BELARBI, A.; MANFAIT, M. FTIR spectroscopic analysis of Saccharomyces cerevisiae cell walls: study of an anomalous strain exhibiting a pink-colored cell phenotype. Federation of European Microbiological Societies Microbiology Letters, Oxford, v. 197, n. 2, p. 179-186, 2001.

GEORGOPAPADAKOU, N. H.; TKACZ, J. S. The fungal cell wall as drug target. Trends in Microbiology, Cambridge, v. 3, n. 3, p. 98-104, 1995.

GERN, R. M. M.; WISBECK, E.; RAMPINELLI, J. R.; NINOW, J. L.; FURLAN, S. A. Alternative medium for production of Pleurotus ostreatus biomass and potential antitumor polysaccharides. Bioresource Technology, Essex, v. 99, n. 1, p. 76-82, 2008.

GIL-AD, N. L.; BAR-NUN, N.; MAYER, A. M. The possible function of glucan sheath of Botrytis cinerea: Effects on the distribution of enzyme activities. Microbiology Letters, Oxford, v. 199, n. 1, p. 109-113, 2001.

GÓMEZ-MIRANDA, B.; PRIETO, A.; LEAL, J. A.; AHRAZEM, O.; JIMÉNEZ-BARBERO, J.; BERNABÉ, $M$. Differences among the cell wall galactomannans from Aspergillus wentii and Chaetosartorya chrysella and that of Aspergillus fumigatus. Glycoconjugate Journal, Dordrecht, v. 20, n. 4, p. 239-246, 2004.

GORIN, P. A. J. Advances in carbohydrate chemistry and biochemistry. New York: Academic Press, 1981. v. 38.

GORIN, P. A. J.; SPENCER, J. F. T. Structures of the L-rhamno-D-mannan from Ceratocystis ulmi and the D-gluco-mannan from Ceratocystis brunnea. Carbohydrate Research, Amsterdam, v. 13, n. 3, p. 339349, 1970.

GUTIÉRREZ, A.; PRIETO, A.; MARTINEZ, A. T. Structural characterization of extracellular polysaccharides produced by fungi from the genus, Pleurotus. Carbohydrate Research, Amsterdam, v. 281, n. 1, p. 143-154, 1996.

HABIJANIČ, J.; BEROVIČ, M.; WRABER, B.; HODŽAR, D.; BOH, B. Immunostimulatory effects of fungal polysaccharides from Ganoderma lucidum submerged biomass cultivation. Food Technology and Biotechnology, Zagreb, v. 39, n. 4, p. 327-331, 2001.

HAHN, M. G.; ALBERSHEIM, P. Host-pathogen interactions. XIV. Isolation and parcial characterization of an elicitor from yeast extract. Plant Physiology, Minneapolis, v. 62, n. 1, p. 107-111, 1978.

HWANG, H.; KIM, S.; CHOI J.; YUN J. Production and characterization of exopolysaccharides from submerged culture of Phellinus linteus KCTC 6190. Enzyme and Microbial Technology, New York, v. 33, n. 2, p. 309-319, 2003.

JIA, L-M.; LIU, L.; DONG, Q.; FANG, J-N. Structural investigation of a novel rhamnoglucogalactan isolated from the fruiting bodies of the fungus Hericium erinaceus. Carbohydrate Research, Amsterdam, v. 339, n. 16, p. 2667-2671, 2004.

JIN, Y.; ZHANG, L.; CHEN, L.; CHEN, Y.; CHEUNG, P. C. K.; CHEN, L. Effect of culture media on the chemical and physical characteristics of polyssaccharides isolated from Poria cocos mycelia. Carbohydrate Research, Amsterdam, v. 338, n. 14, p. 1507-1515, 2003.

JUNQUEIRA, L. C.; CARNEIRO, J. Biologia celular e molecular. 8. ed. Rio de Janeiro: Guanabara Koogan, 2005.

KAPTEYN, J. C.; VAN DEN ENDE, H.; KLIS, F. M. Review:The contribution of cell wall proteins to the organization of the yeast cell wall. Biochimica et Biophysica Acta, Amsterdam, v. 1426, n. 2, p. 373-383, 1999.

KIM, H. O.; YUN, J. W. A comparative study on the production of exopolysaccharides between two entomopathogenic fungi Cordyceps militaris and Cordyceps sinensis in submerged mycelial cultures. Journal of Applied Microbiology, Oxford, v. 99, n. 4, p. 728-738, 2005.

KIM, S. W.; XU, C. P.; HWANG, H. J.; CHOI, J. W.; KIM, C. W.; YUN, J.W. Production and characterization of exopolyasaccharides from an entomopathogenic fungus Cordyceps militaris NG3. Biotechnology Progress, New York, v. 19, n. 2, p. 428-435, 2003.

KIM, Y. O.; PARK, H. W.; KIM, J. H.; LEE, J. Y.; MOON, S. H.; SHIN, C. S. Anti-cancer effect and structural characterization of endo-polysaccharide from cultivated 
mycelia of Inonotus obliquus. Life Sciences, Elmsford, v. 79, n. 1, p. 72-80, 2006.

KLIS, F. M.; BOORSMA, A.; DE GROOT, P. W. J. Cell wall construction in Saccharomyces cerevisiae. Yeast, Chichester, v. 23, n. 3, p. 185-202, 2006.

KLIS, F. M.; MOL, P.; HELLINGWERF, K.; BRUL, S. Dynamics of cell wall structure in Saccharomyces cerevisiae. FEMS Microbiology Reviews, Amsterdam, v. 26, n. 3, p. 239-256, 2002.

KOLLÁR, R.; STURDIK, E.; SAJBIDOR, J. Complete fractionation of Saccharomyces cerevisiae biomass. Food Biothecnology, New York, v. 6, n. 3, p. 225-237, 1992.

KRCMAR, P.; NOVOTNY, C.; MARAIAS, M-F.; JOSELEAU, J-P. Structure of extracellular polysaccharide produced by lignin-degrading fungus Phlebia radiata in liquid culture. International Journal of Biological Macromolecules, Guildford, v. 24, n. 1, p. 61-64, 1999.

KRIZKOVÁ, L.; DURACKOVÁ, Z.; SANDULA, J.; SASINKOVÁ, V.; KRAJCOVIC, J. Antioxidant and antimutagenic activity of yeast cell wall mannans in vitro. Mutation Research, Amsterdam, v. 497, n. 1-2, p. 213-222, 2001.

LEE, J.-N.; LEE, D.-Y.; JI, I.-H.; KIM, G.-E.; KIM, H. N.; SOHN, J.; KIM, S.; KIM, C.-W. Purification of soluble $\beta$-glucan with immune-enhancing activity from the cell wall of yeast. Bioscience Biotechnology and Biochemistry, Tokyo, v. 65, n. 4, p. 837-841, 2001.

LEITE, B.; PASCHOLATI, S. F.; KITAJIMA, W.; ISHIDA, M. L. Mecanismos de adesão de bactérias e fungos às plantas hospedeiras. In: WILMAR, C. L. (Org.). Revisão Anual de Patologia de Plantas. Passo Fundo: RAPP, 2001. v. 9, p. 119-157.

LESAGE, G.; BUSSEY, H. Cell Wall Assembly in Saccharomyces cerevisiae. Microbiology and Molecular Biology Reviews, Washington, v. 70, n. 2, p. 317-343, 2006.

LEUNG, M. Y. K.; LIUB, C.; KOON, J. C. M.; FUNG, K. P. Polysaccharide biological response modifiers. Immunology Letters, Amsterdam, v. 105, n. 2, p. 101114, 2006.

LIMA, P. L. A.; DELMANTO, R. D.; SUGUI, M. M.; EIRA, A. F.; SALVADORI, D. M. F.; SPEIT, G.; RIBEIRO, L. R. Letinula edodes (Berk.) Pegler (Shiitake) modulates genotoxic and mutagenic effects induced by alkylating acents in vivo. Mutation Research, Amsterdam, v. 496, n. 1, p. 23-32, 2001.

LIPKE, P. N.; OVALLE, R. Cell wall architecture in yeast: new structure and new challenges. Journal of Bacteriology, Washington, v. 180 , n. 15, p. 3735-3740, 1998.
LIŽIČÁROVÁ, I.; MATULOVÁ, M.; MACHOVÁ, E.; CAPEK, P. Cell wall mannan of human pathogen Candida dubliniensis. Carbohydrate Polymers, Barking, v. 68, n. 1, p. 191-195, 2007.

MADIGAN, M. T.; MARTINKO, J. M.; PARKER, J. Microbiologia de Brock. 10. ed. São Paulo: Prentice Hall, 2004.

MAGNELLI, P. E.; CIPOLLO.J. F.; ROBBINS, P. W. Glucanase-driven fractioation allows redefinition of Shizoccharomyces pombe cell wall compositon and structure:assigment of diglucan. Analytical Biochemistry, New York, v. 336, n. 2, p. 202-212, 2005.

MARTINICHEN-HERRERO, J. C.; CARBONERO, E. R.; SASSAKI, G. L.; GORIN, P. A. J.; IACOMINI, M. Anticoagulant and antithrombotic activities of a chemically sulfated galactoglucomannan obtained from the lichen Cladonia ibitipocae. International Journal of Biological Macromolecules, Guildford, v. 35, n. 1-2, p. 97-102, 2005.

MENDES-COSTA, M. C.; MORAES, W. B. C. Comparação entre os teores de carboidratos totais solúveis presentes em distintas frações da levedura Saccharomyces cerevisiae. Linhagens de Saccharomyces cerevisiae Meyen. Revista Brasileira de Biologia, Rio de Janeiro, v. 59, n. 1, p. 1-9, 1999.

METHACANON, P.; MADLA, S.; KIRTIKARA, K.; PRASITSIL, M. Structural elucidation of bioative fungiderived polymers. Carbohydrate Polymers, Barking, v. 60, n. 2, p. 199-203, 2005.

MOHAČEK-GROŠEV, V.; BOŽAC, R.; PUPPELS, G. J. Vibrational spectroscopic characterization of wild growing mushrooms and toadstools. Spectrochimica Acta Part A, Amsterdam, v. 57, n. 14, p. 2815-2829, 2001.

MOLINARO, A.; LANZETTA, R.; MANCINO, A.; EVIDENTE, A.; DI ROSA, M.; IANARO, A. Immunostimulant (1.3)-D-glucans from the cell wall of Cryphonectria parasitica (Murr.) Barr strain 263. Carbohydrate Research, Amsterdam, v. 329, n. 2, p. 441-445, 2000.

MONDAL, S.; CHAKRABORTY, I.; PRAMANIK, M.; ROUT, D.; SYED, S.; ISLAM, S. S. Structural studies of water-soluble polysaccharides of an edible mushroom, Termitomyces eurhizus. A reinvestigatio Carbohydrate Research, Amsterdam, v. 339, n. 6, p. 1135-1140, 2004.

MUELLER, A.; RAPTIS, J.; RICE, P. J.; KALBFLESCH, J. H.; STOUT, R. D.; ENSLEY, H.E.; BROWDER, W.; WILLIAMS, D. L. The Influence of glucan polymer structure and solution conformation on binding to $(1,3)$ $\beta$-D-glucan receptors in a human monocyte-like cell line. Glycobiology, Oxford, v. 10, n. 4, p. 339-346, 2000. 
MUZZARELLI, R. A. A.; MILIANI, M.; CARTOLARI, M.; TARSI, R.; TOSI, G.; MUZZARELLI, C. Polyuronans obtained by regiospecific oxidation of polysaccharides from Aspergillus niger, Trichoderma reesei and Saprolegnia sp. Carbohydrate Polymers, Barking, v. 43, n. 1, p. 55-61, 2000.

NELSON, D. L.; COX, M. M. Lehninger, princípios de bioquímica. 3. ed. São Paulo: Sarvier, 2002.

NIMRICHTER, L.; RODRIGUES, M. L.; RODRIGUES, E. G.; TRAVASSOS, L. R. The multitude of targets for the immune system and drug therapy in the fungal cell wall. Microbes and Infection, Paris, v. 7, n. 4, p. 789798, 2005.

NOBEL, H.; VAN DEN ENDE, H. V. D.; KLIS, F. M. Cell wall maintenance in fungi. Trends in Microbiology, Cambridge, v. 8, n. 8, p. 344-345, 2000.

NOMBELA, C.; GIL, C.; CHAFFIN, W. L. Nonconventional protein secretion in yeast. Trends in Microbiology, Cambridge, v. 14, n. 1, p. 15-21, 2006.

PARK, J. P.; KIM, Y. M.; KIM, S. W.; HWANG, H. J.; CHO, Y. J.; LEE, Y. S.; SONG, C. H.; YUN, J. W. Effect of aeration rate on the mycelial morphology and exobiopolymer production in Cordyceps militaris. Process Biochemistry, London, v. 37, n. 11, p. 1257-1262, 2002.

PAVLOVA, K.; PANCHEV, I.; HRISTOZOVA, T. S. Physico-chemical characterization of exomannan from Rhodotorula acheniorum MC. World Journal of Microbiology and Biotechnology, Oxford, v. 21, n. 3, p. 279-283, 2005.

PAZUR, J. H. Neutral polysaccharides. In: CHAPLIN, M. F.; KENNEDY, J. F. Carbohydrate Analysis: A Practical Approach. 2. ed. New York: Oxford University Press, 1994. p. 73-124.

PÉREZ, P.; RIBAS, J. C. Cell wall analysis. Methods, Amsterdam, v. 33, n. 3, p. 245-251, 2004.

PESSONI, R. A. B.; FRESHOUR, G.; FIGUEIREDORIBEIRO, R. L.; HAHN, M. G.; BRAGA, M. R. Cellwall structure and composition of Penicillium janczewskii as affected inulin. Mycologia, New York, v. 97, n. 2, p. 304-311, 2005.

PICCININ, E.; DI PIERO, R. M.; PASCHOLATI, S. F. Efeito de Saccharomyces cerevisiae na produtividade de sorgo e na severidade de doenças foliares no campo. Fitopatologia Brasileira, Brasilia, v. 30, n. 1, p. 5-9, 2005.

POULAIN, D.; JOUAULT, T. Candida albicans cell wall glycans, host receptors and responses: elements for a decisive crosstalk. Current Opinion in Microbiology, Oxford, v. 7, n. 4, p. 342-349, 2004.
PRIETO, A.; LEAL, J. A.; POVEDA, A.; JIMÉNEZBARBERO, J.; GOMEZ-MIRANDA, B.; DOMENECH, J.; AHRAZEM, O. BERNABÉ, M. Structure of complex cell wall polysaccharides isolated from Trichoderma and Hypocrea species. Carbohydrate Research, Amsterdam, v. 304, n. 3-4, p. 281-291, 1997.

REZENDE, M. I.; BARBOSA, A. M.; VASCONCELOS, A. F. D.; HADDAD, R.; DEKKER, R. F. H. Growth and production of laccases by the ligninolytic fungi, Pleurotus ostreatus and Botryosphaeria rhodina, cultured on basal médium contaning the herbicide, Scepter ${ }^{\circledR}$ (imazaquin). Journal of Basic Microbiology, Berlin, v. 45, n. 6, p. 460469, 2005.

RUAS-MADIEDO, P.; LOS REYES-GAVILAN, C. G. Invited review: methods for the screening, isolation, and characterization of exopolysaccharides produced by lactic acid bacteria. Jornal of Dairy Science, Texas, v. 88, n. 3, p. 843-856, 2005.

RUIZ-HERRERA, J. Biosynthesis of beta-glucans in fungi. Antonie Van Leeuwenhoek, v. 60, p. 72-81, 1991.

RUIZ-HERRERA, J.; LEON, C. G.; CARABEZ-TREJO, A.; REYES-SALINAS, E. Structure and Chemical Composition of the Cell Walls from the Haploid Yeast and Mycelial Forms of Ustilago maydis. Fungal Genetics and Biology, Orlando, v. 20, n. 2, p. 133-142, 1996.

SELBMANN, L.; CROGNALE, S; PETRUCCIOLI, M. Exopolysaccharide production from Sclerotium glucanicum NRRL 3006 and Botryosphaeria rhodina DABAC-P82 on raw and hydrolysed starchy materials. Letters in Applied Microbiology, Oxford, v. 34, n. 1, p. 51-55, 2002.

SEVIOUR, R. J.; STASINOPOULOS, S. J.; AUER, D. P. F.; GIBBIS, P. A. Production of pullulan and other exopolysaccharides by filamentous fungi. Critical Reviews in Biotechonology, Boca Raton, v. 12, n. 3, p. 279-298, 1992.

SHAH, V.; RAY, A.; GARG, N.; MADAMWAR, D. Characterization of the extracellular polysaccharide produced by a marine cyanobacterium, Cyanothece sp. ATCC 51142, and its exploitation toward metal removal from solutions. Current Microbiology, New York, v. 40, n. 4, p. 274-278, 2000.

SHARP, J. K.; VALENT, B.; ALBERSHEIM, P. Purification and partial characterization of a $\beta$-glucan fragment that elicits phytoalexin accumulation in soybean. The Journal Of Biological Chemistry, Bethesda, v. 259, n. 18, p. 11312-11320, 1984.

SHIBATA, N., IKUTA, K., IMAI, T., SATOH, Y., SATOH, R., SUZUKI, A., KOJIMA, C., KOBAYASHI, H., HISAMICHI, K. AND SUZUKI, S. Existence 
of branched side chains in the cell wall mannan of pathogenic yeast, Candida albicans; Structureantigenicity relationship between cell wall mannans of Candida albicans and Candida parapsilosis. The Journal of Biological Chemistry, Bethesda, v. 270, n. 3, p. 11131122, 1995.

SILVERSTEIN, R. M. Identificação espectrometrica de compostos orgânicos. 5. ed. Rio de Janeiro: Guanabara Koogan, 1994.

SMITH, G. J.; KAPTEYN, J. C.; VAN DEN ENDE, H.; KLIS, F. M. Cell wall dynamics in yeast. Current Opinion in Microbiology, Oxford, v. 2, n. 4, p. 348-352, 1999.

SUGAWARA, T.; TAKAHASHI, S.; OSUMI, M.; OHNO, N. Refinement of the structures of cell-wall glucans of Schizosaccharomyces pombe by chemical modification and NMR spectroscopy. Carbohydrate Research, Amsterdam, v. 339, n. 13, p. 2255-2265, 2004.

SUGUI, J. A.; LEITE, B.; NICHOLSON, R. L. Partial characterization of the extracellular matrix released by Colletotrichum graminicola onto artificial hydrophobic surface. Physiological and Mololecular Plant Pathology, London, v. 52, n. 6, p. 411-425. 1998.

SUTHERLAND, I. W. Novel and established applications of microbial polysaccharides. Trends in Biotechnology, Amsterdam, v. 16, n. 1, p. 41-46, 1998.

TANG, Y. J.; ZHONG, J. J. Role of oxygen supply in submerged fermentation of Ganoderma lucidum for production of Ganoderma polysaccharide and ganoderic acid. Enzyme and Microbial Technology, New York, v. 32, n. 3, p. 478-484, 2003.

TEIXEIRA, A. Z.; IACOMINI, A.M.; GORIN, P. A. J. Chemotypes of mannose-containing polysaccharides of lichen mycobionts: a possible aid in classification and identification. Carbohydrate Research, Amsterdam, v. 266, n. 2, p. 309-314, 1995.

TORTORA, G. J.; FUNKE, B. R.; CASE, C. L. Microbiologia. 6. ed. Porto Alegre: Artmed, 2000.

VANDAMME, T. F.; LEONOURRY, A.; CHARRUEAU, C.; CHAUMEIL, J. C. The use of polysaccharides to target drugs to the colon. Carbohydrate Polymers, Barking, v. 48, n. 3, p. 219-231, 2002.

WANG, T.; DENG, L.; LI, S.; TAN, T. Structural characterization of a water-insoluble $(1 \rightarrow 3)$ - $\alpha$-D-glucan isolated from the Penicillium chrysogenum. Carbohydrate Polymers, Barking, v. 67, n. 1, p. 133-137, 2007.

WANG, Y:; McNEIL, Production of the fungal exopolisaccharide scleroglucan by cultivation of Sclerotium glucanicum in an airlift reactor with an external loop. Journal Chemical Technology and Biotechnology, London, v. 63, n. 3, p. 215-222, 1995.

WANG, Y.; ZHANG, M.; RUAN, D.; SHASHKOV, A. S.; KILCOYNE, M.; SAVAGE, A. V.; ZHANG, L. Chemical components and molecular mass of six polysaccharides isolated from the sclerotium of Poria cocos. Carbohydrate Research, Amsterdam, v. 339, n. 2, p. 327-334, 2004.

WILLIAMS, D. L. Overview of $(1 \rightarrow 3)-\beta-D-G l u c a n$ immunobiology. Mediators of Inflammation, Oxford, v. 6, n. 4, p. 247-250, 1997.

XIAO, J.; OHSHIMA, A.; KAMKURA, T.; ISHIYAMA, T.; YAMAGUSHI, I. Extracellular glycoprotein(s) associated with cellular differentiation in Magnaporthe grisea. Molecular Plant-microbe Interactions, Saint Paul, v. 7, n. 5, p. 639-644, 1994.

YALIN, W.; CUIRONG, S.; YUANJIANG, P. Studies on isolation and structural features of a polysaccharide from the mycelium of an Chinese edible fungus (Cordyceps sinensis). Carbohydrate Polymers, Barking, v. 63, n. 2, p. 251-256, 2006.

YOUNG, S. H.; JACOBS, R. R. Sodium hydroxideinduced conformational change in schizophyllan detected by the fluorescence dye, aniline blue. Carbohydrate Research, Amsterdam, v. 310, n. 1-2, p. 91-99, 1998.

ZHANG, J.; TANG, O.; ZIMMERMAN-KORDMANN, M.; REUTTER, W.; FAN, H. Activation of B lymphocytes by GLIS, a bioactive proteoglycan from Ganoderma lucidum. Life Sciences, Elmsford, v. 71, n. 6, p. 623-638, 2002.

ZHANG, L.; LI, X.; XU, X.; ZENG, F. Correlation between antitumor activity, molecular weight, and confromation of lentin. Carbohydrate Research, Amsterdam, v. 340, n. 8, p. 1515-1521, 2005.

ZHANG, L.; ZHANG, M.; ZHOU, Q.; CHEN, J.; ZENG, F. Solution properties of antitumor sulfated derivative of $\alpha-(1 \rightarrow 3)$-D-glucan from Ganoderma lucidum. Bioscience, Biotechonology and Biochemistry, Tokyo, v. 64, n. 10, p. 2172-2178, 2000.

ZHANG, M.; CUI, S. W.; CHEUNG, P. C. K.; WANG, Q. Antitumor polysaccharides from mushrooms: a review on their isolation process, structural characteristics and antitumor activity. Trends in Food Science \& Technology, Cambridge, v. 18, n. 1, p. 4-19, 2007.

ZOHURIAAN, M. J.; SHOKROLAHI, F. Thermal studies on natural and modified gums. Polymer Testing, Essex, v. 23, n. 5, p. 575-579, 2004. 
